\title{
Assessing Health and Quality of Life burden on Caregivers of Chronically and Terminally Ill Patients - Evidence Based Systematic Review from a Global Perspective
}

\author{
By Suranjana Datta* \\ Sujoy Kar ${ }^{*}$
}

\begin{abstract}
Care giving for all chronically/terminally ill/incapacitated patients exacts a tremendous toll on the physical, psychosomatic and social health of caregivers. Stressors such as duration of care giving, need of alertness, worsening of disease symptoms, medical management, loss of the care recipient, financial constraints, personal sacrifices, coping strategies, and sometimes the basic lack of awareness towards their own health give rise to poor quality of life for the carers. In this paper we will systematically review the various Interventions taken globally to assess Burden of Caregiver (BoC), determine causal factors and how they affect the quality of life of the caregivers. Data source of citations from five electronic databases (Pubmed, Medline, CINAHL, Embase and Ovid) were searched for the period of last ten years. Systematic reviews that include "end of life care", terminal illness, burden of caregiver (BoC), mental health, psychometrics and care giving were considered including peer reviewed journals.
\end{abstract}

Keywords: Burden of Caregiver (BoC), Caregiver Awareness, Quality of Life (QoL)

\section{Introduction}

The paradigm shift from institutionalized care to community care has resulted in caregivers emerging as key players for patient centered care at homes. Advances and changes in the medical practice have resulted in shorter hospital stay for patients and increased the scope of care giving manifold. There are effects of physical exertion like aggravation of pre-existing chronic illness; a decline/development of distress in basic daily activities or moderate to severe psychological distress (Pinquart and Sorensen 2007). Caregivers are typically defined as unpaid or paid individuals who help a patient or an ill person with his or her activities of daily living. Any person with health impairment might use care giving services to address their difficulties. These may include coordinating care and services and/or providing emotional support (National Cancer Institute). Caregivers may range from parents, children, spouse, sibling and in a lot of other cases are hired for paid caregiving (Stetz and Brown 2004). There are also cultural aspects of care giving. In Taiwan, the caregivers take care giving as a method of repayment to the family members and the beliefs are rooted in Confucianism (Lee et al. 2013).

\footnotetext{
* Assistant Manager, Apollo Gleneagles Hospitals, India.

${ }^{*}$ Director - Medical Services, Apollo Gleneagles Hospitals, India.
} 
Caregiver burden has been defined as a multidimensional response to the negative appraisal and perceived stress resulting from taking care of an ill individual (Zarit et al. 1980). Caregiver burden threatens the physical, psychological, emotional and functional health of caregivers (Zarit et al. 1980). Be it paid or unpaid, caregivers have to cope with a definite burden arising out of caregiving. Burden may often make caregivers feel inadequate and helpless (Valjee and Van Dyk 2014). Reports have been evident regarding physical effects arising out of stress on caregivers that may include frequent headaches, general aches and pains, reduction in appetite, insomnia and common cold (Ogińska-Bulik 2006).

There are enough evidences that caregivers in a lot of cases provide care with minimal or no support for themselves. At least one third of these individuals provides intense care and themselves become prey to poor health. They are at higher risk of emotional, mental and physical health problems which is certainly the result of complex caregiving situations. Their chances of suffering from depression, displaying strategies that are mal - adaptive and expressing more concern about the deteriorating quality of life is high (Serrano-Aguilar et al. 2006, Papastavrou et al. 2007, Molyneux et al. 2008). There is also data to suggest that similar perceptions are shared by both the caregiver and care recipients (with advanced disease) on the index of health care assessment and that they finally evolve as a "unit of care" (Fleming et al. 2006). Caring for others is as important as caring for own self. Much of that is not seen in informal caregivers and in turn significantly contributes to their poor health outcomes.

Among the variables included in the EDAD-2008 survey were the personal characteristics of the persons with disabilities and their caregivers; the characteristics of personal care; and the problems caused by informal caregiving, divided along three different dimensions: health, occupation, and family and social relationships.

Existing research indicates the most common health related problems to be tiredness, exhaustion, acute illness to psychological distress such as anxiety and depression. There are also consistent relationships between measures of perceived burden and depression among caregivers to that of patient's behavioral symptoms and quality of life (Mohamed et al. 2010). The various factors together impaired social and family life of caregivers to a considerable extent. Quality of life of caregivers has also been partially affected by secondary stressors like interpersonal conflicts, social functioning, coping strategies and social support (Cora et al. 2012).

In patients of dementia, the worsening of cognitive and physical abilitieswithout any associative cognitive symptoms (i.e. psychotic, depression or visible change in behaviour) causes a high burden on the caregiver. This indeed is a major problem in terms of health, financial and societal (Ferrara et al. 2008). As evident from research there is a close relation between the duration and severity of disease with that of quality of life of informal caregivers. There have been instances where in order to meet the needs of the in-patient living in the family subjects have changed their habits (Ferrara et al. 2008). There are 
also cases where high level of satisfaction has been noticed in caregivers with clinical depression (Fleming et al. 2006) which in a way prepares them better for handling the stress of caregiving.

Another source of stress that may negatively affect the person who is primarily taking care of the patient can arise out of hostility towards relatives. Carrying out the overwhelming tasks of a caregiver can be challenging and tedious and in turn can give rise to serious issues like anxiety and depression (Sansoni et al. 2004). As seen in a case of Alzheimer's disease it was seen that the burden of responsibility significantly increases in relation to the complexity of the disease and to the depressive state of the caregiver that depends on the severity of the disease (Ferrera et al. 2008). The psychological conditions like anxiety and depression of the care giver, have strong correlations to the scores of the Activities of Daily Living (ADL), Instrumental Activities of Daily Living (IADL), Mini Mental State Examination (MMSE).

It is said that the total number of cancer cases in the United States is expected to double in the next 50 years. The demographic shift, in combination with society's increasing emphasis on controlling health care costs by reducing hospital stays and shifting more care to the outpatient setting, will likely increase the prevalence and need for informal caregiving (Fleming et al. 2006). A clear understanding of determinants of caregiving burden as cancer patients approach death will also help clinicians develop appropriate and effective interventions to reduce caregiving burden (Lee et al. 2013).

Advances in medical treatment has also produced a notable decline in increased hospital stay, decline in mortality and increasing survival years, this in turn has increased the scope of caregiving at home. For HIV infected individuals, these recent advancements have changed the disease from an acute illness to a chronic, debilitating disease. As a result, health-related quality of life (HRQOL) has become an important clinical outcome, and assessing the factors that impact on HIV-infected patients' perceptions of HRQOL have become a major concern for clinicians and researchers in the field in the light of assessing caregiver burden. A large body of previous research has provided important information on the various factors affecting HRQOL (Jia et al. 2004).

Among various coping strategies appraised for an increasing population of male Alzheimer's disease, the likelihood of utilizing three coping strategies were identified and the effect on caregiver burden was measured. Of the three strategies namely task focused, emotion focused and avoidance focused, task focused was reported as the highest reported strategy (Geiger et al. 2014).

\section{Methods}

A systematic literature review was conducted through computer search to review the databases of Pubmed, Medline, CINAHL, Embase, Ovid, Science Direct, BioMed Central. The inclusion criteria for selecting relevant studies are: 
1. Related searches were made by using the key words such as caregivers, quality of life, caregiving, caregiver burden, distress, coping strategies.

2. Other search items included Multiple Sclerosis, Dementia, Alzheimer's disease, Parkinson's disease, Cancer, COPD, HIV/AIDS, chronic illness, palliative care that were used for relevant paper retrieval.

3. All published articles in English language were considered

4. Articles reviewed were published from January 2004 - October 2014

5. Study participants included patients, caregivers or both patient and caregivers in a single study.

6. The studies which were included reported patient/caregiver burden relating to physical, psychological and socio-economic aspects

7. Patients were affected with chronic physical illness, mental illness and/or terminal stage disease state

8. Studies that measured QOL and/or Health related QOL of caregivers and patients

Relevant studies were identified from the electronic data bases. The studies were chosen based on the inclusion criteria and abstracts/full text were screened. The primary reviewer (SD) reviewed the articles first and sent them to the secondary reviewer (SK) for further reviewing. This is because of the relevant expertise and previous experience of the second reviewer in reviewing evidence based studies.

Studies have been chosen and reported by using the PRISMA flow chart for the systematic literature review. The search items were selected keeping the study objectives in mind and also by looking up at the previous literature reviews. General as well as targeted terms were used while looking for relevant literature.

The reviewed articles were finally tabulated focusing on the following attributes:

- Various tools and questionnaires employed in the studies reviewed The ones that measures anxiety and depression, QOL and health status.

- Predictors like patient characteristics.

- Predictors like caregiver characteristics.

\section{Results}

The studies that were reviewed used diverse models and outcomes to indicate Quality of Life of caregivers. Measures like mental health, satisfaction, emotional distress, anxiety, depression, health burden of caregiving encompassed the varied dimensions of psychosocial outcomes affecting QoL.

The results based on the PRISMA flowchart (Figure 1) have been illustrated below. Total number of abstracts identified was 122 out of which 
both the reviewers shortlisted 54 articles. The inclusion/exclusion criteria were applied to these selected articles that yielded 18 articles for final review.

The reviewed studies included participants where caregivers were typically aged between 18-80 years. Caregivers included spouse, children, family member, friends and formal caregivers.

Figure 1. The PRISMA Flowchart

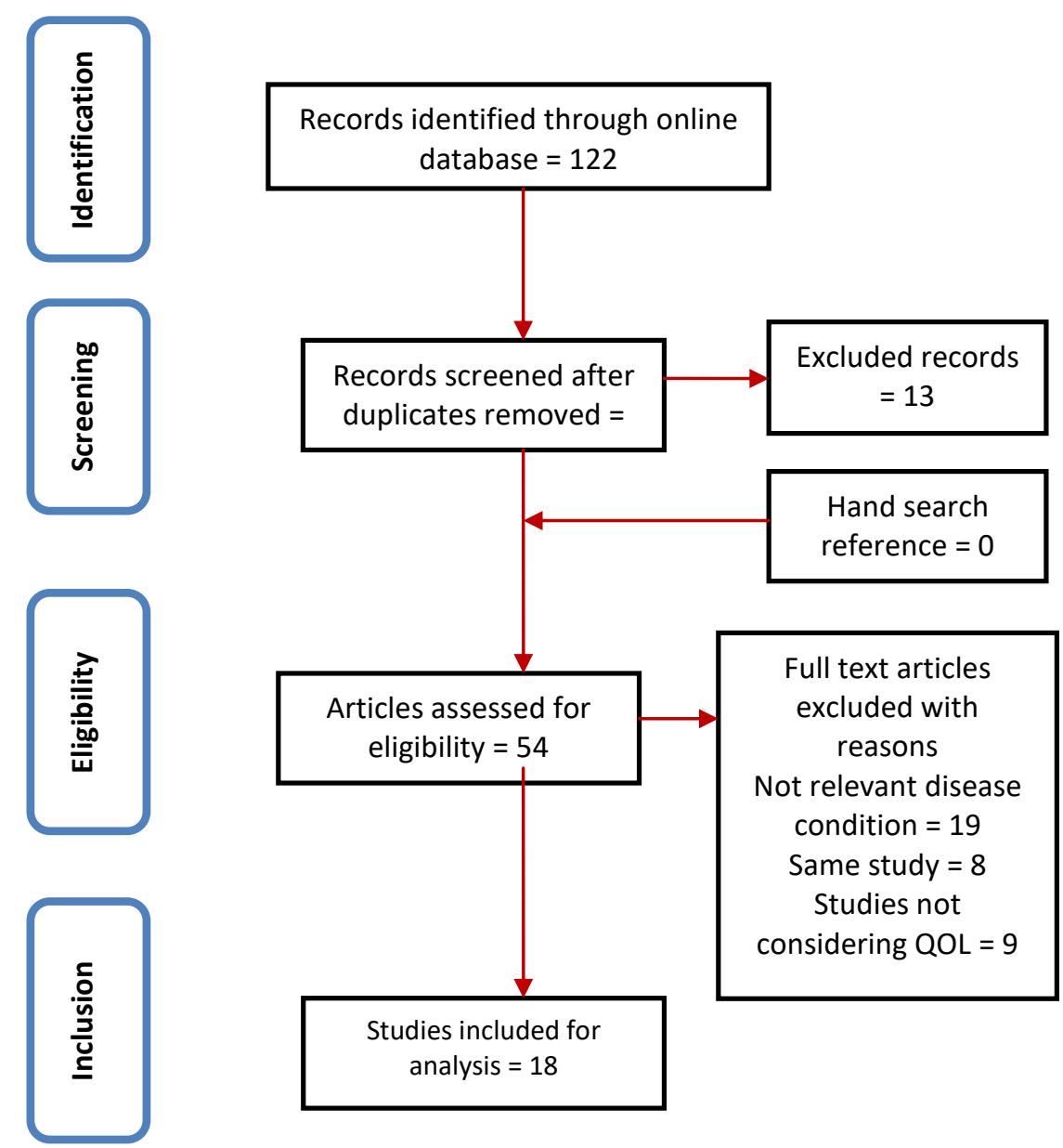

The analysis also revealed the three major categories of predictors. They were caregiver socio-demographical factors, socio demographic and diseaserelated factors of patients and caregiving-related factors; that uniquely explained caregiver burden. Among disease-related factors, reflecting functional decline in care-recipients was the most significant predictor as evident from the review. Socio-demographical characteristics of caregivers also contributed significantly to caregiver stress; these were factors like age, gender, relationship to the patient, employment status and co-residence. They were evident in 7 out of 10 studies.

Of the articles reviewed, two studies that measured QoL used one scale: the Quality of Life scale that has items related to physical, emotional, social, 
and financial wellbeing (Stetz and Brown 2004). Papers reported use of one or more than one instrument/tool, ranging from original or modified patient questionnaire that were based on concepts like burden, general health, and mood status, which were generally indicative of various dimensions related to Quality of Life.

Table 1 shows the various scales and instruments used in the selected studies to measure caregivers' QoL. The use of Hospital Anxiety and Depression Scale (HAD), Beck Depression Inventory, Cornell Scale for Depression and Mini Mental State Examination has been frequently observed in the reviewed studies with HAD being used in 3/18 studies. Apart from these Center for Epidemiological Studies-Depression (CES-D) has also been used in the comparative study for determining physical and psychosocial health in family caregiving of AIDS and Cancer caregivers (Stetz and Brown, 2004)

Table 1. Tools/Questionnaires/Methods of Measurement

\begin{tabular}{|l|}
\hline Tools used for measuring Anxiety and Depression \\
\hline - Hospital Anxiety and Depression Scale (HAD) \\
- Beck Depression Inventory \\
- Brief Psychiatric Rating Scale \\
- Cornell Scale for Depression \\
- Mini Mental State Examination (MMSE) \\
\hline Tools used for measuring Quality of Life and Health Status \\
\hline - Activities of Daily Living Scale \\
- Zarit Burden Inventory Score \\
- Caregiver Distress Scale \\
- Masclach Burnout Inventory \\
- Caregiver Demands Scale \\
- Interpersonal Relationship Inventory \\
- SF-36/SF-26 \\
- Quality of Life Scale \\
\hline Bereavement Items Scale and In-depth interviews were also conducted \\
in certain cases \\
\hline Activities of daily living (ADL) are measured for three dimensions: \\
- Personal-Comprises of eating, dressing, and toileting. \\
- Instrumental ADL-Comprises of housework, laundry, and transportation \\
- Affairs Management-Comprises of legal, financial, and medical affairs \\
\hline
\end{tabular}

\section{Patient Characteristics}

8/18 articles studied the association between patient characteristics (including functional impairment, age, gender, extent of depression, type of illness, general aches and pain, and advanced symptoms in terminal illness) and Quality of Life of caregivers. Generally, significant correlations have been established between caregiver QoL and the patient's physical and emotional 
characteristics in relation to the illness. 7 studies out of 18 found that the patient's performance status, type of illness, and depression were related to the caregiver's QoL. It further revealed that there was a high proportion of caregivers who showed low mental well-being (the norm being 16\%); 7-9 months before death the figure is $30 \%$, at $4-6$ months it is $32 \%$ and at $0-3$ months before the patient's death the figure stands to be $39 \%$ (Butow et al. 2014). One study showed significant relationships between changes in patient symptoms and behavioural problems at six months follow up and changes in caregiver burden (Mohamed et al. 2010). It also revealed relationships between perceived burden and depression among caregivers and patient's psychiatric and behavioural symptoms and QoL.

Table 2 lays down the various predictors that have significantly affected the caregiver Quality of Life. The number of studies reported to show such significance are out of the 18 studies which were included in the analysis. Characteristics that have significantly attributed to higher caregiver burden and the overall quality of life of caregivers are the patient's level of performance, age, gender, anxiety/depression and the type and severity of illness.

Table 2. Patient Characteristics

\begin{tabular}{|l|l|}
\hline Predictors & Significance (Out of 18 studies) \\
\hline Performance Status & Seven studies - Significant Relationship \\
\hline Age & Eight studies - Significant Relationship \\
\hline Gender & Eight studies - Significant Relationship \\
\hline Anxiety/Depression & Seven studies - Significant Relationship \\
\hline $\begin{array}{l}\text { Type/Severity of the } \\
\text { illness }\end{array}$ & Seven studies - Significant Relationship \\
\hline Symptoms at follow up & Two studies - Significant Relationship \\
\hline Quality of Life & Seven studies - Significant Relationship \\
\hline Injuries/Agitation & Three studies - Significant Relationship \\
\hline
\end{tabular}

Injuries, stress and agitation also adds significantly to caregiver burden. As the care recipient starts experiencing physical, emotional and social suffering the psychosocial condition of the caregivers were markedly worsened (Soliman and Almotgly 2011). At the onset of palliative care a substantial psychological morbidity results in increased caregiver burden by the time the patient reaches terminal state. Additional data reveals that compared to $35 \%$ caregivers experiencing anxiety at the start of the palliative period, the figure goes about to $40 \%$ by the time the patients reach the terminal period (Grunfeld et al. 2004).

Although patient characteristics such as age, gender were considered, they did not seem instrumental in changing the dynamics of burden. Rather intermittent hospitalisation has exerted a significant burden. "In all cases, after those hospitalizations, the family caregivers took on added responsibilities for assisting with activities of daily living, such as bathing and feeding, and instrumental activities of daily living, such as shopping, managing the household finances, and taking care of the children" (Schubart et al. 2008: 66). 
As noted by Butow et al. addressing unmet needs is another challenge wherein the severity of such needs increase over time peaking 3-6 months before death but reducing in the last 0-2 months of patient's life (Butow et al. 2014).

\section{Caregiver Characteristics}

As evident from Table 3, eight out of the 18 articles observed the relationship between caregiver characteristics and their QoL. Characteristics such as caregiver's gender, caregiver's age, physical disability, family income, initial QoL, level of education, deteriorating health, anxiety, depression and anger were addressed. Eight out of the eighteen articles studied the association between a caregiver's age and QoL, and five studies reported greater correlation with an age above 50. While studying the relationship between a caregiver's gender and QoL, three of six articles showed that females were more prone to depression.

In addition, the caregiver's physical disability, problem with health, anxiety, depression and anger, were significant enough affecting the QoL negatively.

Table 3. Caregiver Characteristics

\begin{tabular}{|l|l|}
\hline \multicolumn{2}{|l|}{ Caregiver Characteristics } \\
\hline Predictors & \multicolumn{1}{c|}{ Significance } \\
\hline $\begin{array}{l}\text { Age } \\
\text { Age }>50\end{array}$ & $\begin{array}{l}\text { Eight studies - Significant Relationship } \\
\text { Five/Eight studies }\end{array}$ \\
\hline $\begin{array}{l}\text { Gender } \\
\text { Females }\end{array}$ & $\begin{array}{l}\text { Six studies - Significant Relationship } \\
50 \% \text { of the cases more affected }\end{array}$ \\
\hline Physical Disability & Consistently significant \\
\hline Initial QoL & Eight studies - Significant Relationship \\
\hline Anxiety/Depression & Eight studies - Significant Relationship \\
\hline Duration of Caregiving & Five studies - Significant Relationship \\
\hline
\end{tabular}

Caregivers who were older, female, in a spousal relationship or were coresidents experienced significantly higher caregiver burden (eight out of eighteen studies) than caregivers who were young, non-spousal and nonresident caregivers (Kim et al. 2011). Caregivers who provided longer hours and involved in longer periods of caregiving reported higher level of burden and the result was evident in five studies out of eighteen. It was also evident from the analysis that secondary stressors were income, initial quality of life and educational level.

In this light it has been appropriately noted by Ferrera et al. that "53\% of the caregivers declare that they have little time for themselves; they feel that their own social life has been influenced, in some way, whilst $59 \%$ feel emotionally drained" (Ferrera et al. 2008: 95) leading to resentment, anxiety and depression.

Intensity of disease and complications for HIV/AIDS patients also added to traumatic stress. In developing countries the social and cultural conditions 
make the pressure of the stigmatized diseases overwhelming (Soliman and Almotgly 2011).

Demands of care filial obligation had direct positive effects on caregiving involvement (Lee et al. 2013) Involvement and emotion-focused coping had direct positive effects on caregiving burden. Filial obligation, caregiving selfefficacy, and problem-focused coping had direct negative effects on caregiving burden.

\section{Overview of Selected Studies}

As a part of the inclusion criteria, studies considered for analysis where published between 2004 and 2014, with maximum studies published from 2007 onwards (78\%). The country of publication for 8/18 studies is United States of America, with European countries (Italy, Norway, Portugal, Sweden) comprising of $17 \%$ of the total inclusion with one in each country. $2 / 18$ studies have Canada as their country of publication that made up for $11 \%$ of the inclusion. One study each from Australia, Egypt, South Africa and Taiwan were also included in the analysis.

The selected studies showed that $50 \%$ of them had cancer as the disease area under evaluation. Out of these $9 / 18$ Cancer studies, $55 \%$ of them were advanced stage cancers (that comprised of 5/9 studies). HIV/AIDS comprised of $22 \%$, Dementia/Alzheimer's Disease constituted $17 \%$ of the whole, with two cases of COPD and one each of Stroke and Heart Failure. Cross sectional studies were the most common (44\%) with longitudinal and observational studies as the next common ones. Designs apart from these two types included "Meta Analysis" and clinical trials.

Sample characteristics that are evident from Table 4 are:

- All except one study had the mean age of patients above 60 years.

- $11 / 18$ studies showed caregiver's mean age above 50 years.

- $100 \%$ studies included the primary informal caregivers with an exception of one study which also include formal caregivers in a hospice setting.

- $45 \%$ of the included articles have worked with patient, caregiver dyads. 
Table 4. Study and Sample Characteristics

\begin{tabular}{|c|c|c|c|c|c|c|c|c|c|c|c|c|}
\hline \multirow[t]{2}{*}{ SI No. } & \multirow[t]{2}{*}{ Study } & \multirow[t]{2}{*}{ Country } & \multirow[t]{2}{*}{ Study design } & \multirow[t]{2}{*}{ FU } & \multicolumn{2}{|c|}{ Study population } & \multicolumn{2}{|c|}{ Sample Size } & \multicolumn{2}{|c|}{$\begin{array}{l}\text { Mean Age } \\
\text { (in years) }\end{array}$} & \multicolumn{2}{|c|}{ Respondent Gender } \\
\hline & & & & & $\mathbf{P}$ & CG & $\mathbf{P}$ & CG & $\mathbf{P}$ & CG & M & $\mathbf{F}$ \\
\hline 1 & $\begin{array}{c}\text { Butow et al. } \\
(2014)\end{array}$ & AUS & $\begin{array}{c}\text { Prospective } \\
\text { population based }\end{array}$ & No & $\begin{array}{l}\text { Women participating in } \\
\text { Aus. Ovarian Cancer Study }\end{array}$ & $\begin{array}{l}\text { Informal } \\
\text { caregiver }\end{array}$ & \multicolumn{2}{|c|}{99 dyads } & 63 & 59 & $\begin{array}{c}0(\mathrm{P}) \\
80(\mathrm{CG})\end{array}$ & $\begin{array}{c}99(\mathrm{P}) \\
11(\mathrm{CG})\end{array}$ \\
\hline 2 & $\begin{array}{l}\text { Braun et al. } \\
\quad(2007)\end{array}$ & Canada & Cross sectional study & No & $\begin{array}{c}\text { Advanced Gastrointestinal } \\
\text { or Lung cancer }\end{array}$ & Spousal caregiver & \multicolumn{2}{|c|}{101 dyads } & 61.8 & 60 & $24(\mathrm{CG})$ & $77(\mathrm{CG})$ \\
\hline 3 & \begin{tabular}{|c|} 
Bergström et al. \\
$(2011)$
\end{tabular} & Sweden & Cross sectional & Yes & Stroke & $\begin{array}{c}\text { Primary informal } \\
\text { caregiver }\end{array}$ & \multicolumn{2}{|c|}{81 dyads } & 71 & 66 & $\begin{array}{c}67 \%(\mathrm{P}) \\
30 \%(\mathrm{CG})\end{array}$ & $\begin{array}{c}33 \%(\mathrm{P}) \\
70 \%(\mathrm{CG})\end{array}$ \\
\hline 4 & $\begin{array}{c}\text { Figuerido et al. } \\
\text { (2013) }\end{array}$ & Portugal & Cross sectional study & No & $\begin{array}{l}\text { Chronic Obstructive } \\
\text { Pulmonary Disease }\end{array}$ & $\begin{array}{c}\text { Primary caregivers } \\
\text { who provided } \\
\text { maximum support }\end{array}$ & - & 158 & - & 58.3 & 38 & 120 \\
\hline 5 & $\begin{array}{l}\text { Fleming et al. } \\
(2006)\end{array}$ & USA & Cross sectional study & No & Advanced metastatic cancer & Informal caregiver & \multicolumn{2}{|c|}{39 dyads } & 61.7 & 56.2 & $\begin{array}{c}51.3 \%(\mathrm{P}) \\
23.1 \%(\mathrm{CG})\end{array}$ & $\begin{array}{c}48.7 \%(\mathrm{P}) \\
76.9 \%(\mathrm{CG})\end{array}$ \\
\hline 6 & Garlo et al. (2010 & USA & Observational cohort & Yes & $\begin{array}{c}\text { Advanced illness }(\mathrm{Ca}, \text { Heart } \\
\text { failure, COPD) }\end{array}$ & Informal caregiver & \multicolumn{2}{|c|}{179 dyads } & 73 & 62 & $\begin{array}{c}59 \%(\mathrm{P}) \\
22 \%(\mathrm{CG}) \\
\end{array}$ & $\begin{array}{c}41 \%(\mathrm{P}) \\
78 \%(\mathrm{CG})\end{array}$ \\
\hline 7 & Grov et al. (2005) & Norway & RCT & No & $\begin{array}{c}\text { Cancer in late palliative } \\
\text { phase }\end{array}$ & Primary caregiver & - & 96 & - & $\begin{array}{c}56(\mathrm{~F}) \\
66.8(\mathrm{M})\end{array}$ & 37 & 59 \\
\hline 8 & $\begin{array}{c}\text { Grunfeld et al. } \\
(2004)\end{array}$ & Canada & Cross sectional study & Yes & Advanced Breast cancer & Principal caregiver & - & 89 & - & 52.8 & 49 & 40 \\
\hline 9 & Jia et al. (2004) & USA & Cohort study & No & HIV & - & 226 & - & 45.7 & - & 226 & - \\
\hline 10 & Kim et al. (2011) & USA & $\begin{array}{l}\text { Cross sectional } \\
\text { correlation }\end{array}$ & No & Dementia & Informal caregiver & \multicolumn{2}{|r|}{302} & 70.9 & 47.1 & $\begin{array}{c}87(\mathrm{P}) \\
130(\mathrm{CG})\end{array}$ & $\begin{array}{c}205(\mathrm{P}) \\
172(\mathrm{CG})\end{array}$ \\
\hline 11 & Lee et al. (2013) & Taiwan & $\begin{array}{l}\text { Prospective } \\
\text { longitudinal }\end{array}$ & Yes & Terminal cancer & Familial caregiver & - & 193 & - & 46.3 & $31.1 \%$ & $68.9 \%$ \\
\hline 12 & $\begin{array}{c}\text { Ferrera et al. } \\
\quad(2008)\end{array}$ & Italy & $\begin{array}{c}\text { Cross sectional study } \\
\text { (Retrospective) }\end{array}$ & No & Alzheimer's Disease & Informal caregiver & - & 200 & - & 56.1 & 72 & 128 \\
\hline 13 & $\begin{array}{c}\text { Mohamed et al. } \\
(2010)\end{array}$ & USA & $\begin{array}{c}\text { Cross sectional and } \\
\text { longitudinal }\end{array}$ & No & Alzheimer's Disease & Informal caregiver & \multicolumn{2}{|c|}{421 dyads } & 77.9 & 63 & $\begin{array}{c}44 \%(\mathrm{P}) \\
30 \%(\mathrm{CG})\end{array}$ & $\begin{array}{c}56 \%(\mathrm{P}) \\
70 \%(\mathrm{CG})\end{array}$ \\
\hline 14 & $\begin{array}{c}\text { Pinquart and } \\
\text { Sorensen (2007) }\end{array}$ & USA & Meta analysis & $\mathrm{n} / \mathrm{a}$ & $\begin{array}{c}\text { 1. Dementia } \\
\text { 2. Physically frail patients }\end{array}$ & $\begin{array}{l}\text { Both Informal and } \\
\text { Formal caregiver }\end{array}$ & $\mathrm{n} / \mathrm{a}$ & $\begin{array}{c}111 \\
\text { (median) }\end{array}$ & - & 60.6 & - & $74 \%$ \\
\hline 15 & $\begin{array}{l}\text { Schubart et al. } \\
\text { (2008) }\end{array}$ & USA & Observational & No & Brain tumor & Informal caregiver & $\mathrm{n} / \mathrm{a}$ & 25 & - & - & 6 & 18 \\
\hline
\end{tabular}




\begin{tabular}{|c|c|c|c|c|c|c|c|c|c|c|c|}
\hline 16 & \begin{tabular}{|c|} 
Soliman and \\
Almotgly (2011)
\end{tabular} & Egypt & Clinical Trial & No & HIV/AIDS & Primary caregiver & 64 dyads & 35.8 & 39.4 & $\begin{array}{c}45(\mathrm{P}) \\
27(\mathrm{CG})\end{array}$ & $\begin{array}{c}19(\mathrm{P}) \\
38(\mathrm{CG})\end{array}$ \\
\hline 17 & $\begin{array}{c}\text { Stetz and Brown } \\
\text { (2004) }\end{array}$ & USA & $\begin{array}{l}\text { Longitudinal, } \\
\text { comparative }\end{array}$ & Yes & Cancer and AIDS & Primary caregiver & 26 & - & $\begin{array}{c}39 \text { (AIDS) } \\
51(\mathrm{Ca})\end{array}$ & $\begin{array}{c}20 \%(\text { AIDS }) \\
9 \%(\mathrm{Ca})\end{array}$ & $\begin{array}{c}80 \% \text { (AIDS) } \\
91 \%(\mathrm{Ca})\end{array}$ \\
\hline 18 & $\begin{array}{c}\text { Valjee and Van } \\
\text { Dyk (2014) }\end{array}$ & $\begin{array}{l}\text { South } \\
\text { Africa }\end{array}$ & $\begin{array}{c}\text { Exploratory, Mixed } \\
\text { design }\end{array}$ & No & HIV/AIDS & $\begin{array}{l}\text { Formal palliative } \\
\text { caregivers }\end{array}$ & 28 & - & 45.7 & $14.3 \%$ & $85.7 \%$ \\
\hline
\end{tabular}


It is undoubtedly a fact that caregiver health is a rising public health concern and the challenges to address and mitigate it are numerous and the community plays a significant role. The care that has to be meted out to the caregivers must be specialized and customized based on the disease profile they are caring for. As diverse a task as caregiving is, the role changes while caring for a dementia patient with cognitive impairment to that when it is done for a patient with carcinoma in lung. The challenges of care giving for patients with gynecological cancers are again different. The essence has been perfectly captured by Stetz and Brown - "The care giving literature continues to emphasize the critical importance of social support for all groups of caregivers in maintaining health and well-being" (Stetz and Brown 2004: 538).

\section{Discussion}

\section{Key Issues}

Eighteen studies have been reviewed in order to understand the stress related variables and their effects on the caregiver's quality of life. In this process, the factors that were identified included patient characteristics, caregiver characteristics, stressors, coping strategies and social support. It has been observed that family caregivers of persons with terminal cancer and HIV/AIDS patients were quite similar in regards to their experiences of depression, grief, symptoms of stress and overall health (Stetz and Brown 2004). At the later phase of illness the demands of caregiving increases significantly and at that point, more than the diagnosis, it is the reduced functioning of the patient that seem to have greater impact on caregivers.

For palliative caregivers the psychological wellbeing is instrumental for good mental health outcomes and a holistic approach towards caregiving for HIV/AIDS patients turns out to be the most effective approach for better QoL of caregivers (Valjee and Van Dyk 2014). As the disease progresses and the patients are further disabled the relief from the caregiving roles tends to be on the lowest (Schubart et al. 2008). Stress increases with the increased addition of tasks and continuous adaptations to new roles over time. Such is the case in family caregiving for patients with Chronic Obstructive Pulmonary Disease, which involve dealing with complex technologies (home oxygen), multiple medication regimes and treatments for symptom control (airway clearance techniques) (Figueiredo et al. 2013).

\section{Potential Interventions}

- Kim et al. (2011) concluded that while designing screening tools or interventions clinicians should perform a very comprehensive assessment of caregiver's health problems.

- Targeting stressors with higher priority may lead to more effective interventions. 
- Similar views have been shared by Butow et al. (2014) that caregivers of cancer care-recipients would probably benefit from early interaction with psychologists/psychosocial staff for help with managing current and future losses, rather than waiting for post-death referral to bereavement services. Interestingly in this study it was found that treatment was not associated with decreased caregiver QoL, which is probably because of the hope provided by treatment that counter-acts the challenges of side effects and tumour progression (breast cancers).

- Effective communication and interpersonal relationships also play substantial roles in alleviating symptoms of depression (Fleming et al. 2006). So far as socio-demographical factors are concerned it has been observed in the study that spouses are reported to have worse health as they are more prone to show age-related decline; although children are more stressed out with additional work and family responsibilities (Pinquart et al. 2007). Individual predictor such as duration of caregiving and co-residence (Kim et al. 2011) also has remarkable negative impact as health related habits such as engaging in healthy eating patterns and acquiring sufficient sleep is greatly hampered when living with the care-recipient.

- In one of the studies involving patients with AIDS, the caregiver overidentified with the care recipients and suffered from the fear of contagion (Valjee and Van Dyk 2014).

With the increase in life expectancy and the pattern of aging population, chronic disease with its associated disabilities has given rise to increased family caregiving of the aged population. Additional contributing factors are advanced medical technology and constraints in healthcare reimbursement.

This review article summarizes the literature on family and caregiving, that ascertains key issues and notable findings regarding the definition of caregiving, defines the physical and psychiatric health effects of caregiving, and reviews various interventions to improve caregiver burden, depression, and quality of life.

\section{Recommendations}

The review attempted to study patient and caregiver characteristics affecting burden and also offer recommendations to the healthcare providers in accordance with the empirical literature available on family caregiving. This is because a large proportion of caregivers suffering from anxiety and depression reveal that there are always unmet needs, which if addressed at the beginning of the diagnosis can be instrumental for better mental health outcomes of caregivers. 


\section{References}

Butow NP, Price MA, Bell ML, Webb PM, DeFazio A, (2014) Caring for women with ovarian cancer in the last year of life: A longitudinal study of caregiver quality of life, distress and unmet needs. Gynecologic Oncology 132: 690-697

Braun M, Mikulincer M, Rydall A, Walsh A, Rodin G, (2007) Hidden Morbidity in Cancer: Spouse Caregivers. Journal of Clinical Oncology 25(30): 4829-4834

Bergström AL, Eriksson G, von Koch L, Tham K, (2011) Combined life satisfaction of persons with stroke and their caregivers: associations with caregiver burden and the impact of stroke. Health and Quality of Life Outcomes 9(1): 1-10

Cora A, Partinico M, Munafo M, Palomba D (2012) Health risk factors in caregivers of terminal cancer patients: a pilot study. Cancer Nursing 35(1): 38-47.

Ferrara M, Langiano E, Di Brango T, De Vito E, Di Cioccio L, Bauco C (2008) Prevalence of stress, anxiety and depression in with Alzheimer caregivers. Health and Quality of Life Outcomes 6(1): 93-97.

Figueiredo D, Gabriel R, Jacome C, Marques A (2013) Caring for people with early and advanced chronic obstructive pulmonary disease: how do family carers cope?. Journal of Clinical Nursing 23(1-2): 211-220.

Fleming DA, Sheppard VB, Mangan PA, Taylor KL, Tallarico M, Adams I, Ingham J (2006) Caregiving at the end of life: Perceptions of health care quality and quality of life among patients and caregivers. Journal of Pain and Symptom Management 31(5): 407-420.

Garlo K, O’Leary JR, van Ness PH, Fried TR (2010) Burden in Caregivers of Older Adults with Advanced Illness. Journal of American Geriatric Society 58(12): 2315-2322.

Geiger JR, Wilks SE, Lovelace LL, Chen Z, Spivey CA (2014) Burden among male Alzheimer's caregivers effects of distinct coping strategies. American Journal of Alzheimer's Disease and Other Dementias 30(3): 238-246.

Grov EK, Dahl AA, Moum T, Fossa SD (2005) Anxiety, depression, and quality of life in caregivers of patients with cancer in late palliative phase. Annals of Oncology 16(1): 1185-1191.

Grunfeld E, Coyle D, Whelan T, Clinch J, Reyno L, Earle CC, Willan A, Viola R, Coristine M, Janz T, Glossop R (2004) Family caregiver burden: results of a longitudinal study of breast cancer patients and their principal caregivers. Canadian Medical Association Journal 170(12): 1795-1801.

Jia H, Uphold CR, Wu S, Reid K, Findley K, Duncan PW (2004) Health-related quality of life among men with HIV infection: effects of social support, coping, and depression. AIDS Patient Care \& STDs 18(10): 594-603.

Kim H, Chang M, Rose K, Kim S (2011) Predictors of caregiver burden in caregivers of individuals with dementia. Journal of Advanced Nursing 68(4): 846-855.

Lee KC, Chang WC, Chou WC, Su PJ, Hsieh CH, Chen JS, Tang ST (2013) Longitudinal changes and predictors of caregiving burden while providing endof-life care for terminally ill cancer patients. Journal of Palliative Medicine 16(6): 632-637.

Mohamed S, Rosenheck R, Lyketsos K, Schneider LS (2010) Caregiver burden in Alzheimer disease: cross-sectional and longitudinal patient correlates. The American Journal of Geriatric Psychiatry 18(10): 917-927.

Molyneux GJ, McCarthy GM, McEniff S, Cryan M, Conroy RM (2008) Prevalence and predictors of carer burden and depression in carers of patients referred to an old age psychiatric service. International Psychogeriatrics 20(6): 1193-1202. 
Ogińska-Bulik N (2006) Occupational stress and its consequences in healthcare professionals: the role of type $\mathrm{D}$ personality. International Journal of Occupational Medicine and Environmental Health 19(2): 113-122.

Papastavrou E, Kalokerinou A, Papacostas SS, Tsangari H, Sourtzi P (2007) Caring for a relative with dementia: family caregiver burden. Journal of Advanced Nursing 58(5): 446-457.

Pinquart M, Sörensen S (2007) Correlates of physical health of informal caregivers: a meta-analysis. The Journals of Gerontology Series B: Psychological Sciences and Social Sciences 62(2): P126-P137.

Sansoni J, Vellone E, Piras G (2004) Anxiety and depression in community-dwelling, Italian Alzheimer's disease caregivers. International Journal of Nursing Practice 10(2): 93-100.

Schubart JR, Kinzie MB, Farace E (2008) Caring for the brain tumor patient: family caregiver burden and unmet needs. Neuro-oncology 10(1): 61-72.

Serrano-Aguilar PG, Lopez-Bastida J, Yanes-Lopez V (2006) Impact on health-related quality of life and perceived burden of informal caregivers of individuals with Alzheimer's disease. Neuroepidemiology 27(3): 136-142.

Soliman HH, Almotgly MMA (2011) Psychosocial profile of people with Aids and their caregivers in Egypt. Psychological Reports 108(3): 883-892.

Stetz KM, Brown MA(2004) Physical and psychosocial health in family caregiving: a comparison of AIDS and cancer caregivers. Public Health Nursing 21(6): 533540.

Valjee L, Van Dyk AC (2014) Impact of caring for people living with HIV on the psychosocial well-being of palliative caregivers. Curationis 37(1): 1-13

Zarit SH, Reever KE, Bach-Peterson J (1980) Relatives of the impaired elderly: correlates of feelings of burden. The Gerontologist 20(6): 649-655. 
